\title{
3D Simulation and Artificial Neural Networks Application in the Diffusion Study of Champignon Mushroom/Solution Interface During the Salting
}

\author{
Mírian S. P. Bordin, ${ }^{a}$ Hágata C. Silva, ${ }^{a}$ Diego Galvan, ${ }^{\circ}{ }^{a}$ Ana C. G. Mantovani, ${ }^{b}$ \\ Karina B. Angilellia and Dionisio Borsato ${ }^{\circledR *, a}$
}

\author{
${ }^{a}$ Departamento de Química, Universidade Estadual de Londrina (UEL), 86057-970 Londrina-PR, Brazil \\ ${ }^{b}$ Departamento de Física, Universidade Estadual de Londrina (UEL), 86057-970 Londrina-PR, Brazil
}

\begin{abstract}
The influence of the film formed during the salting of champignon mushrooms with brine containing $\mathrm{NaCl}$ and $\mathrm{KCl}$ was modeled using the finite elements method (FEM). It was verified that the film formed on the mushroom surface had a greater influence in the static salting since the diffusion of the ions was 7.5-fold smaller in this system than in the stirred salting. The application of self-organizing maps showed that the ions diffusion along the surface of the solid presented a heterogeneous occurrence and depended on the region for both static and stirred salting. A direct relation was observed among the mushroom surface morphology, the salts diffusion behavior, and the film formation. In addition, the film was not completely extinguished in the stirred system, although it has a minimal influence as the film formation is also dependent on the biosolid surface.
\end{abstract}

Keywords: finite elements method (FEM), artificial neural networks (ANN), mass transfer, modeling, brine

\section{Introduction}

The champignon mushroom (Agaricus bisporus) is one of the three most produced and consumed mushrooms in the world, with China being the main producer. ${ }^{1-3}$

Champignon is a source of vitamin B1, B2, C, niacin, biotin. It presents a low caloric value with high protein content and is also a source of minerals and dietary fiber. ${ }^{4}$ The composition of the champignon mushroom on a dry basis consists of $54.12 \%$ carbohydrate, $28.45 \%$ protein, $5.42 \%$ lipids, and $11.98 \%$ ashes. The fiber content is $20.44 \%$, already included in carbohydrates and proteins. ${ }^{5}$ It is important to emphasize that several amino acids are present in the champignon protein, which is an important factor in the nutritional scope, in which glutamic acid, aspartic acid, and arginine are the most abundant. ${ }^{6}$ However, with a moisture content of approximately $93 \%$, the champignon mushroom is a very perishable food, and therefore, the supply of this product to the population often happens in the pickled form, although it is also sold in its in natura. ${ }^{7}$

The commercialization in the pickled form aims at increasing the shelf life of the product, with salting by

*e-mail: dborsato@uel.br

Editors handled this article: José Walkimar M. Carneiro immersion in an aqueous solution of sodium chloride being the most common method used. This is one of the oldest treatments used for food preservation since this salt, besides presenting antimicrobial action and promoting chemical and nutritional changes, can also improve aroma, texture, and color. ${ }^{8,9}$ However, the relation between $\mathrm{NaCl}$ and health problems as hypertension, osteoporosis, and kidney stones has stimulated the search for the reduction of its levels in food. ${ }^{9-11}$

$\mathrm{KCl}$ is a potential substitute for $\mathrm{NaCl}$ since high potassium ingestion increases the excretion of sodium by the kidneys resulting in an anti-hypertensive effect, in addition to continuing presenting antimicrobial activity. However, sodium cannot be eliminated or replaced without affecting the acceptability of the final product. ${ }^{12}$

Some studies have addressed the diffusion process of $\mathrm{NaCl}$ and $\mathrm{KCl}^{7,12,13}$ The diffusion model between liquids and solids based on Fick's $2^{\text {nd }}$ non-steady-state law, solved by finite elements method (FEM), has obtained good results in helping to understand the phenomena in the diffusion. ${ }^{12,14}$ FEM consists of the domain discretization in several elements. Each element is studied separately so that the equations that describe the phenomenon cease to be differential and become common algebraic equations favoring the problem-solving process. ${ }^{14}$ 
Diffusion is known to occur through the solution occluded in the food, and the mathematical modeling considers the concentration of the solute in homogeneous solids, which can be evaluated through Fick's $2^{\text {nd }}$ Law using an apparent diffusion coefficient of the solute in the liquid. ${ }^{15,16}$ However, according to Schwartzberg and Chao, ${ }^{17}$ when fluids are in contact with solids, a film is formed on the surface. In the event of mass transfer between the surface and the fluid, the flow must pass through the stationary layer, which acts as a resistive barrier, and therefore, there is a diffusion coefficient to describe the mass transfer in that film. The problem is that this coefficient cannot be determined only experimentally and, to evaluate the influence of the film, the ratio between the internal and external mass diffusivity must be taken into consideration, which can be quantified by the mass Biot number. ${ }^{17}$

According to Bona et al. ${ }^{13}$ high values of the Biot number indicate that the internal resistance is limiting and, as this value decreases, the external resistance increases, showing interference of the layer nearest to the solution in the diffusion process. Thus, the Biot number is related to the film coefficient since high Biot values mean that there is no film influence.

In food biosolids, the diffusion on the surface and the formation of the film may be dependent on its geometry and morphology. ${ }^{18}$ Some data analysis tools such as selforganizing maps-type (SOM) artificial neural networks (ANN) are required for better understanding the effects of those factors during the process. ${ }^{19}$ The tool provides results that can be observed through a topological map whose function is to facilitate the results' interpretation. ${ }^{20}$

The purpose of this study was to investigate the influence, formation, and distribution of the film in the multicomponent diffusion of $\mathrm{NaCl}$ and $\mathrm{KCl}$ during the salting process of champignon mushrooms, in static and stirred systems, using 3D computational modeling with the finite element method associated with SOM-type artificial neural networks.

\section{Experimental}

\section{Preparation of the samples and brine}

Champignon mushrooms (Agaricus bisporus) were purchased in the city of São José dos Pinhais-PR, Brazil. Static and stirred brines were prepared with a saline concentration of approximately $3 \%(\mathrm{~m} / \mathrm{v})$ according to Bordin et al. ${ }^{15} \mathrm{~A}$ pump with a $500 \mathrm{~L} \mathrm{~h}^{-1}$ circulation flow was used for agitation.

\section{Scanning electron microscopy (SEM)}

The mushroom microstructures, after being submitted to the brine and cooked, were observed under a field emission scanning electron microscope (SEM) (Eindhoven, Netherlands, FEI, Quanta 200). The samples were prepared according to Bordin et al. ${ }^{15}$

\section{Mathematical modeling}

The mathematical model used was based on the generalization of Fick's $2^{\text {nd }}$ law and Onsager equation. ${ }^{21}$ The finite element formulation considering the simultaneous three-dimensional mass transfer of two solutes in one mushroom is described by Bordin et al. ${ }^{15}$ with some simplifying assumptions made following Angilelli et al. ${ }^{14}$ According to Bordin et al. ${ }^{15}$ the ratio between the internal and external mass transfer resistance can be defined by the Biot mass number $(\mathrm{Bi})$ and has a relation with the mass transfer coefficient $\left(\mathrm{h}_{\mathrm{m}}\right)$ and the mass conductivity coefficient $\left(\lambda_{\mathrm{m}}\right)$ according to equation 1 .

$\mathrm{Bi}=\frac{\mathrm{h}_{\mathrm{m}} \times \mathrm{R}_{\mathrm{i}}}{\lambda_{\mathrm{m}}} ; \mathrm{i}=1,2,3$

where $h_{m}\left(\mathrm{~m} \mathrm{~s}^{-1}\right)$ is the mass transfer coefficient of the solute in the film formed around the mushroom, $\lambda_{\mathrm{m}}\left(\mathrm{m}^{2} \mathrm{~s}^{-1}\right)$ is the mass conductivity, and $\mathrm{R}_{\mathrm{i}}$ is the characteristic dimension corresponding to the semi-distance of the $\mathrm{X}$-axis.

The Biot $(\mathrm{Bi})$ values can also be expressed as:

$\mathrm{Bi}=\frac{\mathrm{h}_{\mathrm{m}} \times \mathrm{m} \times \mathrm{a}}{\mathrm{D}_{\mathrm{ii}}}$

Knowing the value of the diffusion coefficient $\left(\mathrm{D}_{\mathrm{ii}}\right)$, the $h_{m}$ term can be determined from equation $2,{ }^{17}$ where $m$ corresponds to the ratio between the concentrations of the diffusion component in the mushroom and the solution in infinity, and $\mathrm{a}=\mathrm{R}_{\mathrm{i}}$.

\section{Simulation by finite element method}

The simulation was performed using the COMSOL Multiphysics $^{\circledR}$ software (COMSOL, Inc., Burlington, MA). ${ }^{22}$ The following parameters were used in the simulation: main diffusion coefficients, crossed diffusion coefficients, and mass Biot number, adjusted by Bordin et al. ${ }^{15}$ Figure 1 presents the solid generated by the software, with all simulations being performed with a 3D geometry modeling, with the area previously subdivided into a tetrahedral finite element mesh comprised of 163,080 elements with 
60,430 degrees of freedom; the mean dimensions of the mushrooms used in the simulation and convention were adopted for the imaginary axis.

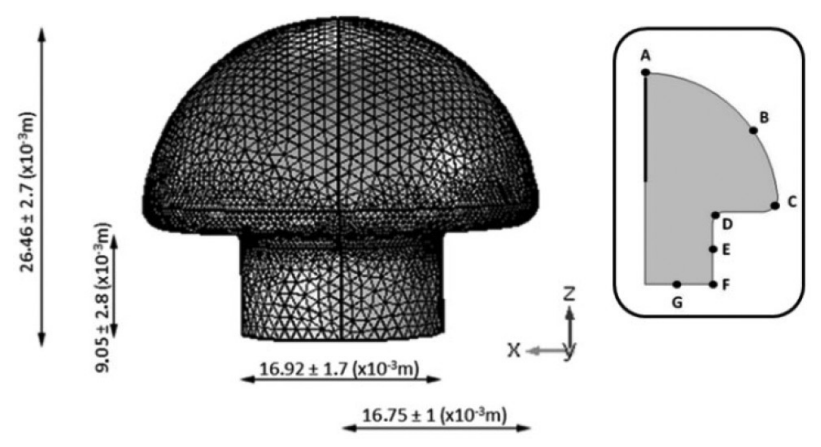

Figure 1. Average dimensions and reference points used.

\section{SOM-type artificial neural network}

The Kohonen self-organizing map (SOM) algorithm begins by initializing the first grid with random synaptic weights and no organization applied to the map. After initialization, three key processes take place: competition, cooperation, and synaptic adaptation. ${ }^{19,23}$

The SOM applied to each ion in each isolated system consists of a $4 \times 4$ hexagonal topology with 10,000 training epochs. The initial neighborhood relationship was 1.0, with an initial learning rate of 0.2 , decaying exponentially with the training epochs to $9.08 \times 10^{-6}$.

\section{Computational processing}

The COMSOL Multiphysics ${ }^{\circledR}$ version 5.2 (COMSOL, Inc., Burlington, MA), ${ }^{22}$ a software package based on FEM, was used to simulate the influence of the film formed during the multicomponent diffusion of $\mathrm{NaCl}$ and $\mathrm{KCl}$ in different systems. The neural network routine was used according to the algorithm described in Haykin ${ }^{23}$ and was processed by the MATLAB ${ }^{\circledR}$ R2007 software ${ }^{24}$ (The MathWorks Inc.; Natick, MA) to evaluate the $\mathrm{NaCl}$ and $\mathrm{KCl}$ concentrations in $\mathrm{mol} \mathrm{m}^{-3}$ at points A, B, C, D, E, F, G (Figure 1) and surface in different times, which were tabulated and presented to the neural network.

\section{Results and Discussion}

The main and cross coefficients and the Biot number were used to determine the influence of the film's diffusion coefficient on the mushroom surface during the static and stirred brine. Simulations were performed at the following times: $0,0.001,0.01,0.02,0.05,0.1,0.25,0.5$, $1,2,3,4,5,6,7,8,9,10,11,13,15,17,19,21,23,25$,
$27,29,35,40,45,50,65,70,75,80,85,90,95,100,150$ and $200 \mathrm{~h}$.

According to the results, the main and cross coefficients were the same for both systems, which is a consistent result, since the diffusion inside the same food does not depend on the boundary conditions. The cross coefficients for potassium ions are 2.4-fold lower than the sodium's, which indicates that the diffusion of sodium ions has greater interference than the potassium diffusion. The cross coefficients being smaller than the main coefficients means that the gradient diffusion is more important than the diffusion due to the interference from a solute in the flow of the other one. ${ }^{12,25,26}$

The main diffusion coefficient for potassium was slightly higher than the sodium coefficient. The results were expected since they consider that the diffusion of salts in biosolids takes place within the occluded water presenting higher diffusion coefficients for the potassium ions. The ionic radii of $\mathrm{K}^{+}$and $\mathrm{Na}^{+}$are 151 and $118 \mathrm{pm}$, respectively. Therefore, the highest charge density is attributed to the $\mathrm{Na}^{+}$ ions, which have a higher ion-dipole interaction with water molecules and consequently a higher hydration radius and lower ion mobility. ${ }^{27}$

Unlike the main and cross coefficients, the Biot number is dependent on the boundary conditions with the solid/ solution interface. It can be interpreted as the ratio of the internal to the external diffusion resistance. Thus, for high Biot values, diffusion becomes less dependent on external resistance. ${ }^{13,17}$ In this way, the stirred system is less dependent on the external resistance, with a Biot number of 600; while the static system presents a Biot number of 79.56. This may be quite an abstract interpretation of what this external resistance represents. Therefore, this topic requires further studies to find better interpretive conditions regarding the transport phenomena between phases, and how they may influence the diffusion process.

The phenomena of mass transfer between phases are complex and can be interpreted in several ways. One of the theories suggests that the transfer resistance in each stage is located on a surface film near the interface. ${ }^{28}$ According to Coulson and Richardson, ${ }^{28}$ the film can be interpreted as a physical barrier, where no substance accumulates, and the value of $h_{m}$ depends on both the species concentration gradient and the film thickness.

According to equations 1 and 2, Biot is directly proportional to the film coefficient $h_{m}$, that is the higher the film coefficient, the greater the Biot and the lower the influence of external resistance. From the main coefficients, it is possible to determine $h_{m}$ according to equation 2 . The values obtained are presented in Table 1.

Comparing the film coefficients obtained for sodium 
Table 1. Adjusted values for main and cross-diffusion coefficients, mass Biot number, and film coefficient

\begin{tabular}{|c|c|c|c|c|}
\hline & \multicolumn{2}{|c|}{ Static brine } & \multicolumn{2}{|c|}{ Stirred brine } \\
\hline & $\mathrm{Na}^{+}$ & $\mathrm{K}^{+}$ & $\mathrm{Na}^{+}$ & $\mathrm{K}^{+}$ \\
\hline Main coefficient $/\left(\mathrm{m}^{2} \mathrm{~s}^{-1}\right)$ & $2.692 \times 10^{-10}$ & $2.953 \times 10^{-10}$ & $2.692 \times 10^{-10}$ & $2.953 \times 10^{-10}$ \\
\hline Cross coefficient $/\left(\mathrm{m}^{2} \mathrm{~s}^{-1}\right)$ & $0.716 \times 10^{-10}$ & $0.297 \times 10^{-10}$ & $0.716 \times 10^{-10}$ & $0.297 \times 10^{-10}$ \\
\hline Mass Biot number & 79.56 & & 600 & \\
\hline $\mathrm{h}_{\mathrm{m}} /\left(\mathrm{m} \mathrm{s}^{-1}\right)$ & $1.277 \times 10^{-6}$ & $1.402 \times 10^{-6}$ & $9.64 \times 10^{-6}$ & $10.57 \times 10^{-6}$ \\
\hline
\end{tabular}

Adapted from Bordin et al. ${ }^{15} \mathrm{~h}_{\mathrm{m}}$ : mass transfer coefficient.

and potassium in the same system, it was observed that the values obtained for potassium were slightly higher. The film coefficients were 7.5 higher for both ions in the stirred system when compared to the static one. This result is adequate because, according to the interpretation adopted for the film, its influence is dependent on its thickness-the thinner the film, the easier the passage of the ions and therefore, the greater the diffusion coefficients in the film. The application of a perturbation in the system makes the film thinner when compared to the static system. The increased agitation applied in the present study could further reduce the film thickness, however, the speed increase could compromise the mushrooms' integrity.

Figure 2 presents the concentration variation along the semi-straight shown in bold in the Z-axis in Figure 1, as a
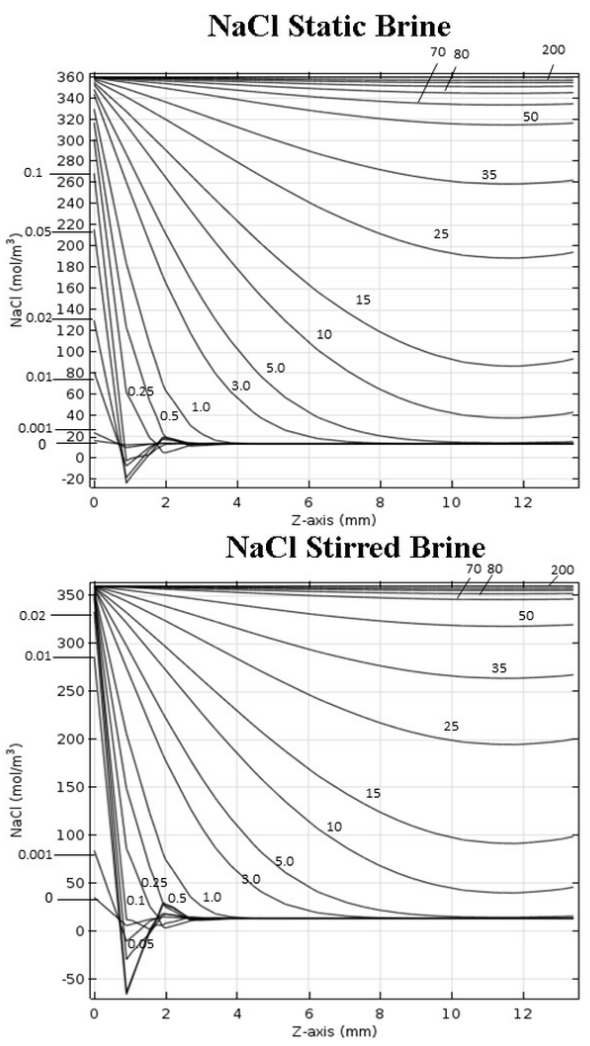

function of the diffusion times obtained by the simulation of the salting process.

The line graphs show the influence of the film formed during the diffusion process, where point $0 \mathrm{~mm}$ represents the biosolid surface and point $12 \mathrm{~mm}$ represents its interior. It is possible to visualize how the salt concentrations on the surface of the solid change as a function of the concentration gradient. The mushrooms presented initial $\mathrm{K}^{+}$and $\mathrm{Na}^{+}$ concentrations of 40.78 and $13.37 \mathrm{~mol} \mathrm{~m}^{-3}$, respectively. Thus, it is not possible that the salt concentration is smaller than the initial one in any extension of the mushroom, and any value in the graph that is smaller than the values of the initial concentrations is caused by the oscillation of the method used in the simulation.

The $\mathrm{K}^{+}$and $\mathrm{Na}^{+}$concentrations in the brine are 120

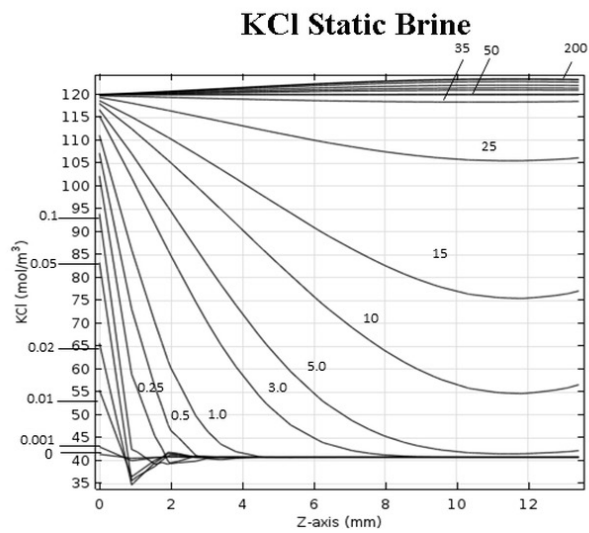

KCl Stirred Brine

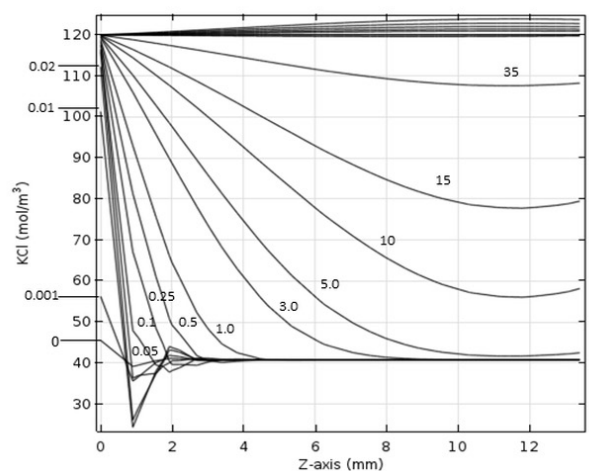

Figure 2. Distribution profile of the salt concentration at $0,0.001,0.01,0.02,0.05,0.1,0.25,0.5,1.0,3.0,5.0,10,15,25,30,70,70,80,90,150$ and $200 \mathrm{~h}$ of the multicomponent diffusion simulation process on the mushroom Z-axis (mm). 
and $360 \mathrm{~mol} \mathrm{~m}^{-3}$, respectively. If there were no influence of the film, the salt concentration on the biosolid surface should be equal to the concentration of the solution at the beginning of the salting process, that is, at time $0 \mathrm{~h}$. There is no system or salt in which this happened; however, there were big differences between the stirred and static systems for the same ion. For sodium in the static system, the surface concentration was $270.16 \mathrm{~mol} \mathrm{~m}^{-3}$ at time $0.1 \mathrm{~h}$, while the concentration was $348.19 \mathrm{~mol} \mathrm{~m}^{-3}$ in the stirred system at the same moment. The same behavior can be observed for the potassium ion, when the concentration of the surface was $94 \mathrm{~mol} \mathrm{~m}^{-3}$ in the static system, it was $116.3 \mathrm{~mol} \mathrm{~m}^{-3}$ in the stirred one at the same time. The stirred system always presented higher surface concentration values when compared to the static one for both ions.

Table 2 presents the ion concentration percentage on the mushroom surface for the brine value, at random times during the simulation. In this way, it is clearer and simpler to analyze the existence and the influence of the film for the different ions in both systems.

Table 2. Percentage of the species concentration on the surface in relation to the concentration in the brine

\begin{tabular}{lccccc}
\hline & \multicolumn{2}{c}{ Stirred brine } & & \multicolumn{2}{c}{ Static brine } \\
\cline { 2 - 3 } \cline { 5 - 6 } & $\mathrm{Na}^{+}$ & $\mathrm{K}^{+}$ & & $\mathrm{Na}^{+}$ & $\mathrm{K}^{+}$ \\
\hline Brine $/\left(\mathrm{mol} \mathrm{m}^{-3}\right)$ & 360 & 120 & & 360 & 120 \\
$0.001 \mathrm{~h} / \%$ & 32 & 53 & & 8 & 37 \\
$0.5 \mathrm{~h} / \%$ & 98 & 99 & & 88 & 90 \\
$100 \% \%^{\mathrm{a}} / \mathrm{h}$ & 15 & 4 & & 45 & 21 \\
\hline
\end{tabular}

${ }^{a}$ Time required for the ion concentration on the surface to equilibrate with the concentration in the brine.

The values indicate that there is a greater influence of the film in the static system, which has lower concentration percentages when compared to the stirred system. In
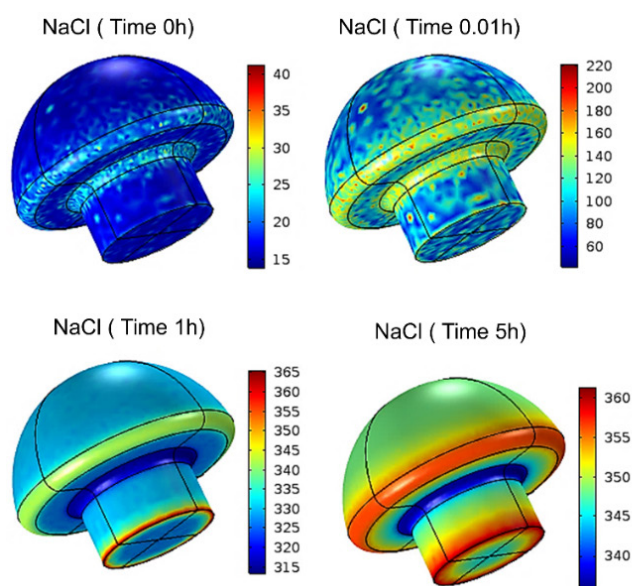

both systems, the percentage of sodium is lower than the percentage of potassium. In other words, the rate of sodium mass transfer in the film is lower than potassium. At $0.5 \mathrm{~h}$, for the stirred system, the ion concentration values are greater than $98 \%$, almost equal to the surface concentration. In the static system, both ions concentrations did not exceed $90 \%$. It took 15 and $4 \mathrm{~h}$ for $\mathrm{Na}^{+}$and $\mathrm{K}^{+}$to reach the equilibrium between the solution and surface in the stirred system, and 45 and $21 \mathrm{~h}$ for the static system, respectively. The time interval from 0.001 to $0.5 \mathrm{~h}$, which already presents a high concentration, and the time of equilibrium is due to the dependence of the mass transfer rate on the concentration gradients. The more the concentration on the surface approaches the solution concentration, the lower is the concentration gradient and the slower is the diffusion.

To verify the influence of the biosolid geometry on the formation of the film and consequently on the salts diffusion, Figures 3 and 4 present the 3D images of the multicomponent diffusion on the biosolid surface at different time intervals $(0-200 \mathrm{~h})$ of the simulation, for the $\mathrm{Na}^{+}$and $\mathrm{K}^{+}$ions in the static system.

Figures 3 and 4, shown by the color scale, indicate different ion concentrations on the surface along with the entire discretized geometric domain. From the beginning of the diffusion, the formation of a region with higher ions concentration around points $\mathrm{C}$ and $\mathrm{F}$ (Figure 1) can be observed. A region of lower concentration around point $\mathrm{D}$ (Figure 1) can also be observed, while in the other points there is a region of intermediate concentration. The same interpretation can be made for the stirred system.

Although Figures 3 and 4 suggest that there is a difference in diffusion as a function of the biosolid geometry, such data are not sufficient to prove this behavior, since a conventional statistical analysis is not enough to prove whether or not these differences are significant. Thus, there is the need to perform a complementary behavior
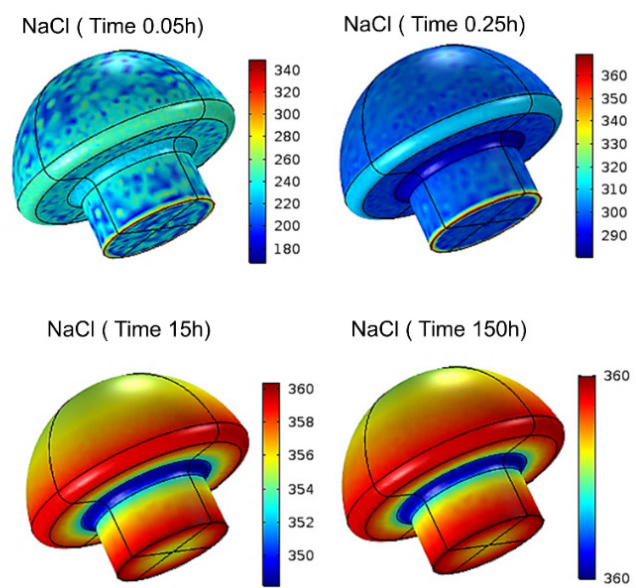

Figure 3. Distribution of 3D concentration of $\mathrm{Na}^{+}\left(\mathrm{mol} \mathrm{m}^{-3}\right)$ on the biosolid surface in the static system at different times. 


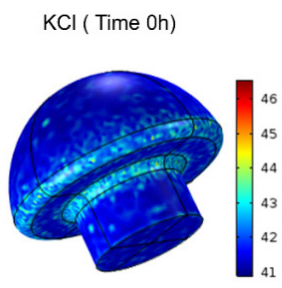

$\mathrm{KCl}$ ( Time 1h)

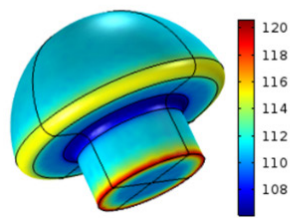

$\mathrm{KCl}$ ( Time $0.01 \mathrm{~h}$ )

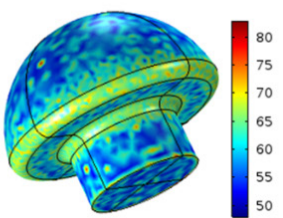

$\mathrm{KCl}$ ( Time 5h)

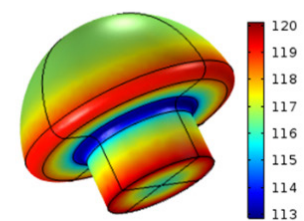

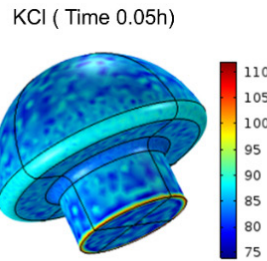

KCl ( Time 15h)

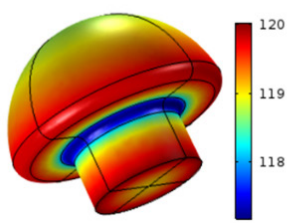

$\mathrm{KCl}$ ( Time 0.25h)

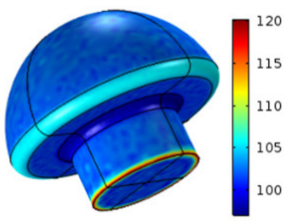

KCl ( Time 150h)

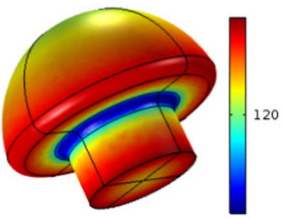

Figure 4. Distribution of $3 \mathrm{D}$ concentration of $\mathrm{K}^{+}\left(\mathrm{mol} \mathrm{m}^{-3}\right)$ on the biosolid surface in the static system at different times.

study of this biophysical process with the application of SOM-type ANN, which is based on not very conventional statistical principles. ${ }^{19,23}$

The values of $\mathrm{Na}^{+}$and $\mathrm{K}^{+}$concentrations at points A, B, C, D, E, F, and G (Figure 1), as well as the total concentration on the mushroom surface at the simulated times, were presented for the SOM network for the diffusion analysis in both systems (Figure 5).

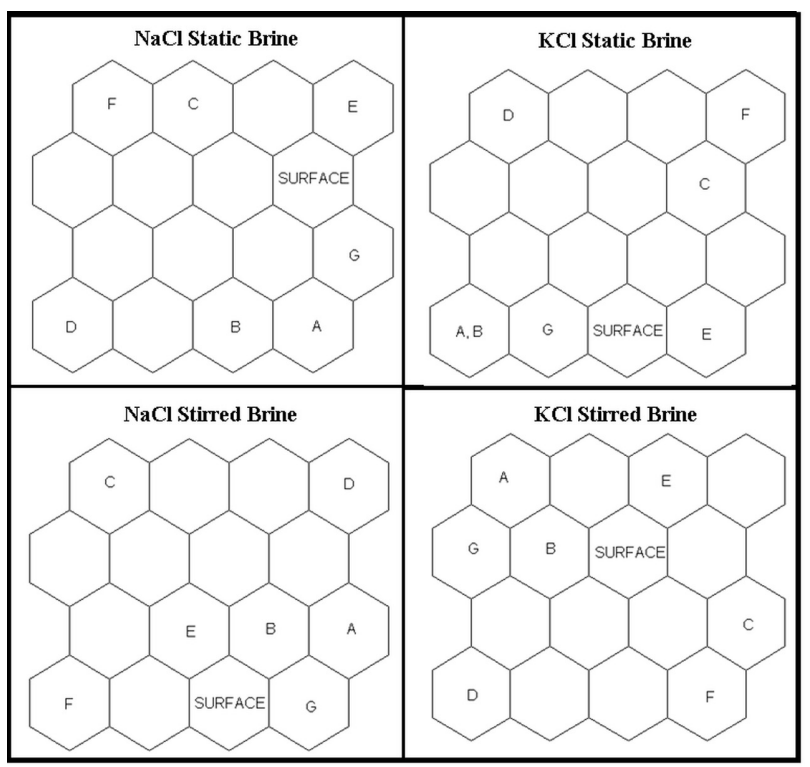

Figure 5. Distribution of the analyzed points (Figure 1) according to the neuron for each ion and independent system.

The distribution map (Figure 5) presents the classification of points A, B, C, D, E, F, and G, and the total surface in relation to the concentration for each ion and independent system. The SOM network classifies the input data in the form of clusters that can be formed by one or more neurons. ${ }^{19}$ The groups' definition is characterized by the presence of empty neurons between the clusters, and thus, it can be concluded that the network was able to identify differences in the diffusion process with geometry. The groups formed for the potassium ion in both systems and sodium in the static system were the same. In those three situations, three distinct groups could be identified.

The first group consists of points $\mathrm{C}$ and $\mathrm{F}$, which correspond to the extremities with more prominent convex curvatures; in these regions, the salt concentrations reach the highest values in relation to the others. The second group is formed only by point $\mathrm{D}$, the region of concave curvature located between the top of the mushroom and its stem. This region presents the lowest concentrations of salts. The third group is formed by points A, B, E, G, and the surface. This group represents the geometric regions of the biosolid where the concentrations are intermediate between the two groups previously mentioned. The points in this group represent regions of the biosolid with less pronounced curvatures, such as points $\mathrm{A}$ and $\mathrm{B}$, or even regions with no curvature, such as points $\mathrm{E}$ and $\mathrm{G}$.

The only difference in the stirred system for the sodium ion in relation to the others was that points $\mathrm{C}$ and $\mathrm{F}$ are no longer part of the same group, with each of them now corresponding to an individual group. However, they are still the points of highest salts concentration. These results relate to the salts concentration as a function of the biosolid region angle, and it requires greater morphology knowledge of those regions to understand the phenomena responsible for such differences.

Figure 6 shows the images of the surface regions around points $\mathrm{A}, \mathrm{C}$, and $\mathrm{E}$ of the mushrooms (Figure 1). Point B was not analyzed due to the difficulty in determining its real location experimentally, and point $\mathrm{D}$ was not analyzed because it was a thin layer surrounding the mushroom lamellae and, therefore, it was not possible to isolate the tissue since it would practically be disintegrated upon cutting, making its analysis impossible. 
In addition, points $\mathrm{F}$ and $\mathrm{G}$ were not analyzed because the mushroom stems were cut for sample standardization during the experiment, and therefore, their surface had the interference of cutting blades which compromised the analysis of the surface.

The first analysis was carried out to verify if the salting could influence the surface morphology of the biosolid. In general, the salting caused little changes to the surface morphology, with changes being evident only at points $C$ and E. Before salting, the filaments that make up the surface were organized more homogeneously, in a "side-by-side" manner, almost on the same plane. After salting, it can be observed that some filaments stand out concerning the others, and they are more twisted.

When comparing the morphological differences among the surfaces in points $\mathrm{A}, \mathrm{C}$, and $\mathrm{E}$, it can be noted that the regions for points $\mathrm{A}$ and $\mathrm{E}$ have a larger filament grouping; that is, the organization occurs in a compact form, without empty spaces between them. The more compact they are, the less space is occupied by the solution, making the salt diffusion in these regions more difficult. In addition, this compaction eases the film formation since it is a relatively more uniform surface.

The region of point $\mathrm{C}$ is formed by less compacted filaments, presenting a greater disorder and larger gaps between the filaments with the other points. Thus, a greater amount of solution can occupy the region, easing the ions' mobility and their diffusion. This filaments disorganization may be a detrimental factor in the formation of the film, which would further facilitate diffusion. These conclusions comply with the results obtained by the neural network, which indicated similarity of diffusion in points $\mathrm{A}$ and $\mathrm{E}$, classifying them in the same group and differentiating them from the region formed by point $\mathrm{C}$.

\section{Conclusions}

The diffusion process is hampered due to the influence of the film formed at the biosolid/solution interface, which varies according to the type of system employed and the biosolid geometry. As expected, the film presented greater interference in the diffusion of both ions in the static system, since stirring makes the film formation difficult. With stirring, it was possible to increase the value of the film coefficient and decrease the external resistance, facilitating the entrance of the ions on the mushroom surface. The influence of the film between the ions in the same system was higher for the sodium ion. The FEM simulation allied to the SOM-type ANN showed the dependence of the salt diffusion with the formed film and the geometry of the mushroom, in both salting systems used. Microscopic analysis showed that the immersion salting process caused a little alteration into the morphological properties of the mushroom surfaces compared with the mushroom that was only cooked. However, the comparison of the different analyzed regions can justify the different diffusion behaviors indicated by ANNs, suggesting that the film is formed in a heterogeneous manner and that it is dependent on the biosolids' morphology.

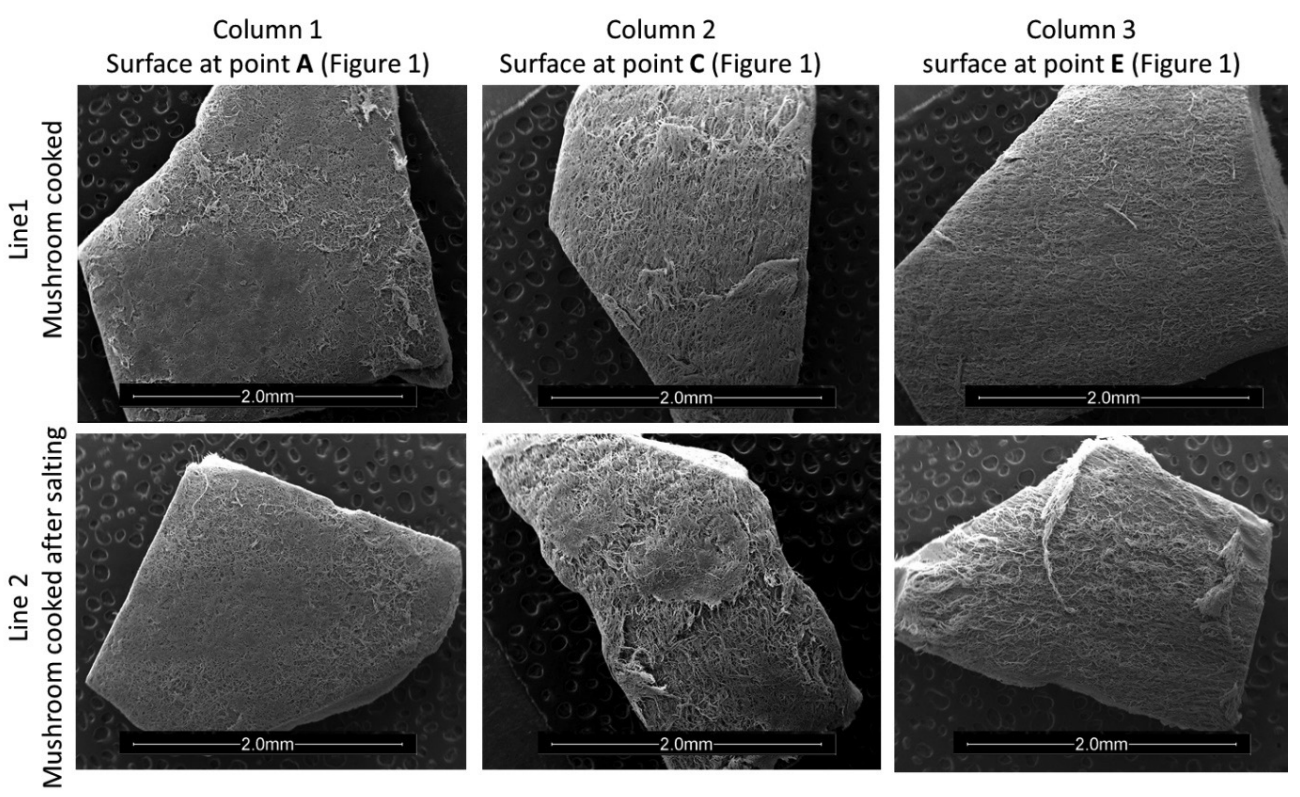

Figure 6. Microscopic images of the surface of the precooked mushroom (line 1) and after $48 \mathrm{~h}$ immersion (line 2), for points $\mathrm{A}, \mathrm{C}$, and $\mathrm{E}$ in static brine. Bar scale: $2.0 \mathrm{~mm}(50 \mathrm{x})$. 


\section{Acknowledgments}

The State University of Londrina (UEL) and CAPES are acknowledged for scholarships. The authors would also like to thank the Laboratory of Electron Microscopy and Microanalysis (LMEM) UEL/FINEP.

\section{Author Contributions}

Mírian S. P. Bordin was responsible for conceptualization, data curation, formal analysis funding acquisition; validation; Hágata C. Silva for project administration, software, validation, visualization; Diego Galvan for project administration, software, validation, visualization; Ana C. G. Mantovani for conceptualization, writing original draft, writing-review and editing; Karina B. Angilelli for conceptualization, investigation, project administration, writing original draft, writing review and editing; Dionisio Borsato for conceptualization, formal analysis funding acquisition, investigation, project administration, resources; writing original draft.

\section{References}

1. Sánchez, C.; Appl. Microbiol. Biotechnol. 2010, 85, 1321.

2. Choudhary, D. K.; Int. J. Microbiol. 2011, 2011, ID 790285.

3. Kozarski, M.; Klaus, A.; Jakovljevic, D.; Todorovic, N.; Vunduk, J.; Petrović, P.; Niksic, M.; Vrvic, M.; van Griensven, L.; Molecules 2015, 20, 19489.

4. Reis, F. S.; Barros, L.; Martins, A.; Ferreira, I. C. F. R.; Food Chem. Toxicol. 2012, 50, 191.

5. Furlani, R. P. Z.; Godoy, H. T.; Cienc. Tecnol. Aliment. 2007, 27, 154.

6. Manzi, P.; Gambelli, L.; Marconi, S.; Vivanti, V.; Pizzoferrato, L.; Food Chem. 1999, 65, 477.

7. Albarracín, W.; Sánchez, I. C.; Grau, R.; Barat, J. M.; Int. J. Food Sci. Technol. 2011, 46, 1329.

8. Santapaola, J.; Maldonado, S.; Medina, J. L.; J. Food Eng. 2013, $118,172$.

9. Thibaudeau, E.; Roy, D.; St-Gelais, D.; Int. Dairy J. 2015, 40, 54.

10. Doorenbos, C. J.; Vermeij, C. G.; BMJ 2003, 326, 35.
11. He, F. J.; MacGregor, G. A.; BMJ 2001, 323, 497.

12. Borsato, D.; Moreira, M. B.; Moreira, I.; Pina, M. V. R.; Silva, R. S. S. F.; Bona, E.; Food Sci. Technol. 2012, 32, 281.

13. Bona, E.; Carneiro, R. L.; Borsato, D.; Silva, R. S. S. F.; Fidelis, D. A. S.; Silva, L. H.; Braz. J. Chem. Eng. 2007, 24, 337.

14. Angilelli, K. G.; Orives, J. R.; da Silva, H. C.; Coppo, R. L.; Moreira, I.; Borsato, D.; J. Food Process. Preserv. 2015, 39, 329.

15. Bordin, M. S. P.; Borsato, D.; Cremasco, H.; Galvan, D.; Silva, L. R. C.; Romagnoli, É. S.; Angilelli, K. G.; Food Chem. 2019, 273, 99 .

16. Cussler, E. L.; Multicomponent Diffusion, vol. 3; Elsevier Scientific Publishing Company: Pittsburgh, USA, 1976.

17. Schwartzberg, H. G.; Chao, R. Y.; Food Technol. 1982, 36, 73.

18. Gonzales-Perez, J. E.; Lopes-Mendes, E. M.; Ochoa-Velasco, C. E.; Ruiz-Lopes, I. I.; J. Food Eng. 2019, 262, 181.

19. Cremasco, H.; Borsato, D.; Angilelli, K. G.; Galão, O. F.; Bona, E.; Valle, M. E.; J. Sci. Food Agric. 2016, 96, 306.

20. Kohonen, T.; Self-Organizing Maps; Springer Series in Information Sciences: Berlin, Heidelberg, 1995.

21. Onsager, L.; Ann. N. Y. Acad. Sci. 1945, 46, 241.

22. Comsol Multiphysics ${ }^{\circledR}$, version 5.2; COMSOL, Inc., Burlington, MA, USA, 2016.

23. Haykin, S.; Redes Neurais: Princípios e Prática; Bookman Editora: Ontário, Canada, 2007.

24. Matlab $^{\circledast}$, version 7b; The MathWorks Inc.; Natick, MA, USA, 2007.

25. Borsato, D.; Moreira, I.; Nóbrega, M. M.; Moreira, M. B.; Silva, R. S. S. F.; Bona, E.; Quim. Nova 2009, 32, 2109.

26. Bordin, M. S. P.; Cremasco, H.; Galvan, D.; Clemente, M. A. J.; Bona, E.; Mantovani, A. C. G.; Borsato, D.; J. Braz. Chem. Soc. 2020, 31, 1101.

27. Lee, J. D.; Concise Inorganic Chemistry, $5^{\text {th }}$ ed.; Champman \& Hall: London, 1996.

28. Coulson, J. M.; Richardson, J. F.; Chemical Engineering, $2^{\text {nd }}$ ed.; Pergamon Press: London, UK, 1965.

Submitted: June 24, 2021 Published online: November 22, 2021 